\title{
Effects of Implant Thread Geometry on Percentage of Osseointegration and Resistance to Reverse Torque in the Tibia of Rabbits
}

\author{
Jennifer Steigenga, ${ }^{*}$ Khalaf Al-Shammari, ${ }^{\dagger}$ Carl Misch, ${ }^{\ddagger}$ Francisco H. Nociti Jr., ${ }^{\S}$ and Hom-Lay Wang ${ }^{\ddagger}$
}

Background: Dental implant thread geometry has been proposed as a potential factor affecting implant stability and the percentage of osseointegration. Therefore, the aim of this prospective, randomized, parallel arm study was to evaluate the effects of dental implant thread design on the quality and percent of osseointegration and resistance to reverse torque in the tibia of rabbits.

Methods: Seventy-two custom-made, screw-shaped, commercially pure titanium implants $(3.25 \mathrm{~mm}$ diameter $\times 7 \mathrm{~mm}$ length) were placed in the tibiae of 12 white New Zealand rabbits. Each tibia received three implants of varying thread shapes: one with a Vshaped, one with a reverse buttress, and one with a square thread design. The rabbits were sacrificed following an uneventful healing period of 12 weeks. Implants in the right tibiae underwent histologic and histomorphometric assessments of the bone-to-implant contact $(\mathrm{BIC})$ and the radiographic density of surrounding bone, while implants in the left tibiae were used for reverse-torque testing. Differences between the three thread designs were examined using analysis of variance (ANOVA).

Results: Data showed that the square thread design implants had significantly more BIC and greater reverse-torque measurements compared to the V-shaped and reverse buttress thread designs, while no differences were found in radiographic bone density assessments.

Conclusion: These results indicate that the square thread design may be more effective for use in endosseous dental implant systems. J Periodontol 2004;75:1233-1241.

\section{KEY WORDS}

Dental implants, endosseous; dental prosthesis design; dental prosthesis, implant supported; osseointegration.

\footnotetext{
* Currently, private practice, Lansing, MI; previously, Department of Periodontology/ Prevention/Geriatrics, School of Dentistry, University of Michigan, Ann Arbor, MI.

$\dagger$ Department of Periodontology/Prevention/Geriatrics, School of Dentistry,

University of Michigan; Ministry of Health, Kuwait.

‡ Department of Periodontology/Prevention/Geriatrics, School of Dentistry, University of Michigan.

$\S$ Department of Prosthodontics and Periodontics, Division of Periodontics, School of Dentistry at Piracicaba, University of Campinas, São Paulo, Brazil.
}

A major advance in dentistry has been the successful replacement of lost natural teeth by osseointegrated implants. The use of dental implants for the oral rehabilitation of fully and partially edentulous patients has greatly broadened the scope of clinical dentistry and allowed for the inclusion of patients and cases not previously possible. The predictability and long-term success of dental implants have been well documented, both in removable and fixed prostheses. ${ }^{1-4}$ Most of the studies reported have shown multi-year success rates of more than $90 \%$ for implants or partially edentulous patients. 3,5-10

Nevertheless, success rates have been reported to vary in different areas of the mouth and in different patients. For example, lower success rates have been reported for maxillary implants than for mandibular implants. ${ }^{1,11,12}$ Attempts have been made to understand the factors that may compromise implant success. Factors such as material biocompatibility, implant design and surface, surgical technique, host bed, and the loading conditions have all been shown to influence implant osseointegration. ${ }^{13}$ Available bone volume has long been considered as an important factor in achieving implant predictability. ${ }^{14}$ Studies showed higher failure rates for implants shorter than $10 \mathrm{~mm}^{2}$ Another important influencing factor for implant success is bone density, since higher failure rates have been reported for regions with poor quality bone, e.g., the posterior maxilla. ${ }^{11,15-17}$ 
Consequently, modifications in implant body design and implant surfaces have been suggested to increase the success in poor quality bone by, hypothetically, gaining better anchorage and providing more surface area of load to decrease stress to the softer bone types. ${ }^{11}$ Carlsson et al. ${ }^{18}$ found a more complete bone-to-implant contact around screw-shaped implants than around double cylinders and T-shaped implants, and a stronger biomechanical bond with a rough implant surface than with a similarly shaped but polished implant surface. Other studies have also reported that a rough surface is more suitable for implant integration than a comparatively smoother implant surface by demonstrating a higher degree of bone integration. ${ }^{19-22}$

Surface roughness is not the only implant design criterion to consider for optimal osseointegration. Finite element analysis studies of implants indicate that bone stress distributions and magnitudes vary with implant shape. ${ }^{23,24}$ Identifying the ideal implant shape and material has been challenging, as the optimum bone stress state remains unknown. However, it is known and accepted that bone responds differently to different types of loading and is weakest under shear loading conditions. ${ }^{25}$ Transforming shear forces into more resistant force types at the bone interface is the purpose of incorporating threads into the implant design as a surface feature. Threads are also used to maximize initial contact, improve initial stability, enlarge implant surface area, ${ }^{26}$ and favor dissipation of interfacial stress. ${ }^{27}$ Thread depth, thread thickness, face angle, pitch, and helix angle are some of the varying geometric patterns that determine the functional thread surface and affect the biomechanical load distribution of the implant. ${ }^{28}$ The available thread shapes of square, $\mathrm{V}$-shape, and reverse buttress are intended to reduce the development of shear forces at the dental implant-tissue interface, therefore improving long-term success. ${ }^{29}$

Several thread designs have been developed. The original Branemark screw, introduced in 1965, had a $\mathrm{V}$-shaped thread pattern as a means of placement into a threaded osteotomy. ${ }^{30}$ The original design has been modified over the years to allow for simpler, more efficient placement and better load distribution. The standard V-shaped thread, called a fixture in engineering, has 10 times greater shear loads on bone compared with a square thread with parallel major and minor diameters. ${ }^{28}$ Reverse buttress thread shape is optimized for pull-out loads and has parallel major and minor diameters. ${ }^{31}$ The reverse buttress thread design has fewer threads and less thread depth.

Square thread shape, called a power thread in engineering, reportedly provides an optimized surface area for intrusive, compressive load transmission, resulting in a lower strain profile to bone. ${ }^{28}$ In an animal study using the square thread implants, it was reported that bone grew between the threads, closely adapted to the implant, and that the inferior aspect of the test implant threads were apposed by more bone than the coronal aspect. ${ }^{29}$ These results suggest a biological advantage for the compressive load transfer mechanism for this thread design. This observation was further supported in the case report of two bioengineered square thread design implants $\|$ loaded for 1 year. ${ }^{31}$ It was demonstrated in the case report that the bone was primarily lamellar in structure, the bone turnover rate was less than 5 $\mu \mathrm{m} /$ day, and was the same as the bone away from the interface. However, due to limited sample sizes, additional histologic reports and clinical data are required to confirm the observations made in these reports.

Limited information is currently available on the influence of implant thread design on overall implant success rate, and no direct comparisons of the available thread designs have been reported. Therefore, the aim of this prospective, randomized, parallel arm study was to evaluate the effects of dental implant thread design on the quality and percent of osseointegration and resistance to reverse torque in the tibia of rabbits.

\section{MATERIALS AND METHODS}

This prospective, randomized, parallel arm study investigated the influence of implant thread design characteristics on resulting bone quality. A power calculation was performed to determine the sample size, and it was determined that a minimum of 10 animals were necessary to achieve power. The influence of dental implant thread design on the quality and percent of osseointegration and bone remodeling were evaluated in the tibiae of 12 female white rabbits (Oryctolagus cuniculus), 9 to 12 months of age, with a weight ranging from 3.4 to $4.1 \mathrm{~kg}$. The tibiae of each rabbit received three study implants $(3.25 \mathrm{~mm} \times 7 \mathrm{~mm})$, one each of the V-shaped, buttress, and square thread designs (Fig. 1).

For each animal, the implants in the left tibia were used for biomechanical testing (removal torque test), and the implants in the right tibia were used for histological examination. The implants were placed transcortically and alternated in location to account for reported bone quality differences in different regions of the rabbit tibia. ${ }^{32}$ This stratification in implant position (distal, medial, or proximal portion of the upper tibia) was performed as described previously. 20

The study protocol was approved by the University Committee on Use and Care of Animals at the University of Michigan. Housing was in standard cages for rabbits, and feeding of the animals was according to national standards for laboratory animals. Prior to surgery, animals were acclimated to the vivarium for a period of observation to ensure that they were healthy and stable.

|| Maestro, BioHorizons Implant Systems, Birmingham, AL. 


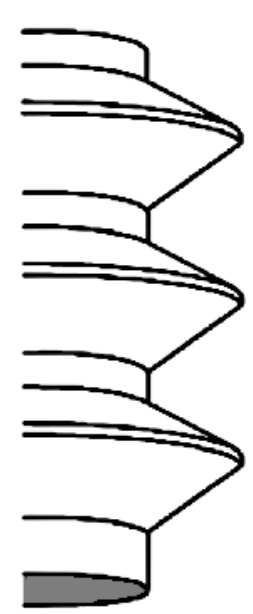

Standard V-Thread

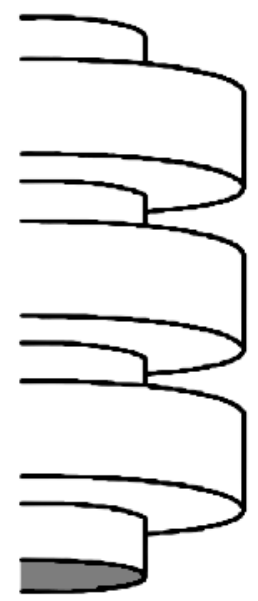

Square Thread

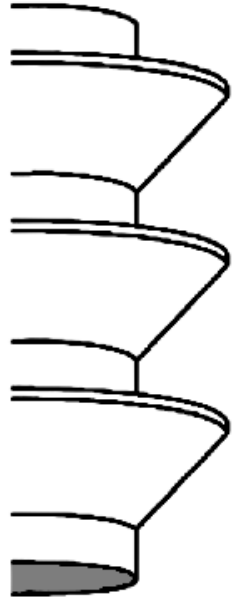

Buttress Thread

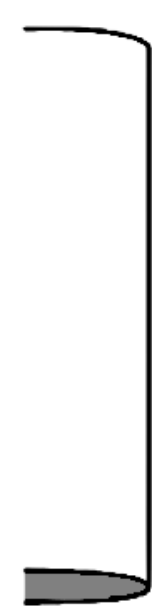

Non-Threaded

Figure I.

Standard thread shapes in dental implant design. The $V$, square, and reverse buttress threads were evaluated in this study.

\section{Study Implants}

A total of 72 custom-made, screw-shaped, commercially pure titanium implantsll were used in this study. All thread designs used are available through commercial firms; however, we arranged to have all 72 implants custom made by one manufacturer to avoid any potential bias. All implants had a uniform thread pitch, the same fixed number of threads per unit length in the same axial plane and on the same side of the axis, as well as uniform thread depth throughout the length of the implant. Implants were $3.25 \mathrm{~mm}$ in diameter by $7 \mathrm{~mm}$ in length. The implant thread design was the only variation: $24 \mathrm{~V}$ thread, 24 reverse buttress thread, and 24 square thread design (Fig. 1). The study implants did not have holes, grooves, or slots to resist rotation.

One surface was used on all implants to reduce the influence of surface roughness variability on bone response. The implants were roughened through a process known as resorbable blast media (RBM), where hydroxyapatite particles were used as the biocompatible blast media to obviate surface contamination from the blasting process. ${ }^{33}$ The blast media resorbs during the passivation process, resulting in an optimum roughness profile of a pure $\mathrm{TiO}_{2}$ surface free of contaminants. This roughened surface is superior in increasing biological fixation and improving implant-to-bone contact over a machined surface. ${ }^{33}$

\section{Surgical Procedures and Implant Placement}

The rabbits were anesthetized with a combination of $1.3 \mathrm{cc}$ of ketamine $(100 \mathrm{mg} / \mathrm{ml})$ and $0.2 \mathrm{cc}$ xylazine $(8.8 \mathrm{mg} / \mathrm{kg}$ ) intramuscularly followed by continuous inhalation delivery of $1.0 \%$ to $2.0 \%$ isofluorane (u.s.p.) before the surgical procedures. The legs were shaved, washed, and decontaminated with betadine prior to ster- ile draping. Surgical exposure was accomplished with an incision through the skin, fascia, and periosteum at the medial side of the proximal tibia using sterile surgical techniques.

Implant site osteotomies were prepared in the usual manner using drills with increasing diameter under profuse irrigation with sterile saline. The implants were screwed into place without pre-tapping the sites, until the implant shoulder was level with the bone surface. All implants penetrated the first cortical layer only, never engaging the opposite cortical plate. Each rabbit received a total of six implants, three implants in each the right and left tibiae, one each of the different thread designs. The implants were uniformly stratified bilaterally with placement and retrieval performed by the same surgeon. After the implants were seated and stable, the surgical sites were closed in two layers and sutured to obtain primary closure using resorbable gut sutures.

Post-procedurally, each animal was given $0.3 \mathrm{cc}$ of buprenophine hydrochloride ${ }^{\mathbb{I}}$ and 2 cc of enrofloxacin ${ }^{\#}$ $(22.7 \mathrm{mg} / \mathrm{ml})$ intramuscularly. For the next 2 days postoperatively, each animal received 2 cc of enrofloxacin by mouth, once in the morning and once at night. Animals were given water and fed ad libitum while healing, with full weight-bearing capacity immediately after surgery.

\section{Torque Measurements}

Twelve weeks post-surgically, all 12 rabbits were anesthetized. The implant sites in the left tibiae were surgically exposed via sharp dissection to bone and clinically examined after careful removal of overgrowing bone and soft tissues. An implant removal mount was securely fastened, engaging the external hex, which was connected to the torque gauge with the insertion device. Removal torque tests were performed on all implants in the left tibiae using a torque gauge manometer** with a measuring range from 0 to $150 \mathrm{~N}-\mathrm{cm}$. After stabilizing the legs, torque was increased incrementally by rotating the gauge slowly counterclockwise. Manual torquing continued until loosening of the implants was detected with the peak torque value recorded when rupture occurred between implant and bone. Peak torque measurements were recorded by a single examiner masked to the implant thread design. Mean torque measurements were calculated for each implant thread design.

\section{Histologic Preparation of Specimens}

Immediately after the biomechanical testing and removal of the implants in the left tibiae, the animals were sacrificed by administration of $1.75 \mathrm{cc}$ pentobarbital

I Buprenex, Reckitt Benckiser Healthcare, Hull, U.K.

\# Baytril, Bayer Healthcare LLC, Shawnee Mission, KS

** Mark-10, Hicksville, NY. 
(390 $\mathrm{mg} / \mathrm{ml}$, IV, to effect) via the ear vein. The right tibiae of all of the rabbits were removed at sacrifice (12 weeks postoperatively), and soft radiographs were taken for initial orientation of the implants prior to sectioning. All soft radiographs ${ }^{\dagger \dagger}$ were taken at the Medical College of Georgia, Augusta, Georgia, with occlusal film at $55 \mathrm{KvP}$ and $2.5 \mathrm{MA}$ for 60 seconds. Routine radiographs of the tissue samples for densitometric analysis were taken by a radiographic unit ${ }^{\ddagger}$ with occlusal film at $55 \mathrm{KvP}$ and 2.5 MA for one second.

Each implant region was dissected and block biopsies including implant and surrounding tissues were obtained and fixed in 10\% neutral buffered formalin. Each portion of the block biopsy contained three implants of the tested thread designs. These fixed tissues were sent to a histology laboratory at the Medical College of Georgia School of Dentistry. They were dehydrated using ascending grades of alcohol, infiltrated, and embedded in methyl methacrylate (MMA) for non-decalcified sectioning. ${ }^{34}$ For histomorphometric analysis, several serial sections, $250 \mu \mathrm{m}$ thick, were taken in the long axis of each implant as close to the midline as possible using a diamond wire saw. $\$ \S$ These sections were milled to a thinner measurement $(\leq 100 \mu \mathrm{m})$ utilizing a grinder/ polisher ${ }^{\| l}$ to maximize microstructure and viewing resolution. The sections were polished to an optical finish and stained with modified masson trichrome stain for histomorphometric and histological analyses. The boneto-implant contact length fraction (BIC\%) was measured from the bottom of the thread shoulder using the internal and external angles of the first three threads of the implant length for the various groups. This was done under one microscopic view at a time for a specific area.

Histometric analyses and microscopic observations were performed by one examiner. Microscopic images

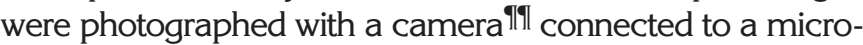
scope $^{\# \#}$ and transferred to a personal computer. These images were analyzed with image analysis software. *** The percentage of bone-to-implant contact around the threads was calculated using a $10 \mathrm{X}$ objective lens.

\section{Statistical Analysis}

Mean values of bone-to-implant contact for the three different thread designs were calculated and subjected to one-way and repeated measures analysis of variance. Differences in mean peak removal torque values and radiographic bone density were compared for significance by a repeated measures analysis of variance. Statistical testing was carried out at the $5 \%$ significance level $(P<0.05)$.

\section{RESULTS}

\section{Clinical Observations}

All of the rabbits tolerated the implantations well, regaining full weight-bearing mobility within a few days postoperatively. No fractures or complications were
Table I.

$$
\begin{aligned}
& \text { Reverse Torque Removal Values (N-cm) } \\
& \text { and Percentage of Bone-to-Implant Contact } \\
& \text { (BIC) ( } \mathrm{N}=12 \text { rabbits) }
\end{aligned}
$$

\begin{tabular}{|c|c|c|c|}
\hline & V-Thread & $\begin{array}{l}\text { Reverse } \\
\text { Buttress } \\
\text { Thread }\end{array}$ & $\begin{array}{l}\text { Square } \\
\text { Thread }\end{array}$ \\
\hline $\begin{array}{l}\text { Reverse torque } \\
\text { value } \\
\qquad(\mathrm{N}=36 \text { implants })\end{array}$ & $15.58 \pm 6.07^{*}$ & $15.46 \pm 6.22^{\dagger}$ & $23.17 \pm 9.68 * \dagger$ \\
\hline $\begin{array}{l}\text { Percentage of } \mathrm{BIC} \\
\qquad\left(\mathrm{N}=69 \text { implants }^{\ddagger}\right)\end{array}$ & $65.46 \pm 9.64 *$ & $63.05 \pm 12.45^{\dagger}$ & $74.37 \pm 8.63 * \dagger$ \\
\hline
\end{tabular}

noted during the 12 -week healing period. Rabbits 7 and 11 were diagnosed with ear mites 2 weeks postoperatively and both were treated successfully with topical medication. At sacrifice, no signs of gross infection, tissue reaction, or any other pathology were noted around the implant sites. Radiographically, no gross changes to the tibial architecture were noted, however some endosteal bone formation and consolidation were seen. Three of the implant specimens were not readable; therefore, analyses were performed on 69 implants.

\section{Removal Torque Measurements}

Twelve weeks after implant placement, the mean removal torque was $15.58 \pm 6.07 \mathrm{~N}$-cm for the $V$-thread implants, $15.46 \pm 6.22 \mathrm{~N}$-cm for the reverse buttress thread implants and $23.17 \pm 9.68 \mathrm{~N}$-cm for the square thread implants. The torque measurements yielded statistically significant differences between the square thread group compared to both the V-thread or the reverse buttress group $(P<0.05)$ (Table 1$)$. The highest removal torque was found in the square thread implant group, while the V-thread group demonstrated the lowest. No significant differences in removal torque were found between the V-thread and the reverse buttress thread implants (Table 1 ).

\section{Histologic Evaluation}

Microscopically, all 36 implants were well integrated into bone. Implants were in contact with cortical bone along the upper threads, while the lower threads were in con-

\footnotetext{
$\dagger \dagger$ Faxitron Series 43807N Radiographic System, Hewlett-Packard, Palo Alto, CA.

㧊 Toshiba, San Jose, CA.

$\S \S$ Well Precision Diamond Wire Saw, Inc., Mannheim, Germany.

III Ecomet III, Buehler, Ltd., Lake Bluff, IL.

If Digital Spot Camera, Diagnostic Instruments, Inc., Sterling Heights, MI.

\#\# Axiophot, Carl Zeiss, Oberkochen, Germany.

$* * *$ Version 6.00.10, Bioquant Image Analysis Corporation, Nashville, TN.
} 
tact with either newly formed bone or with normal marrow tissue (Fig. 2). Fibrous tissue was absent between bone and implant surfaces for all groups. Due to the
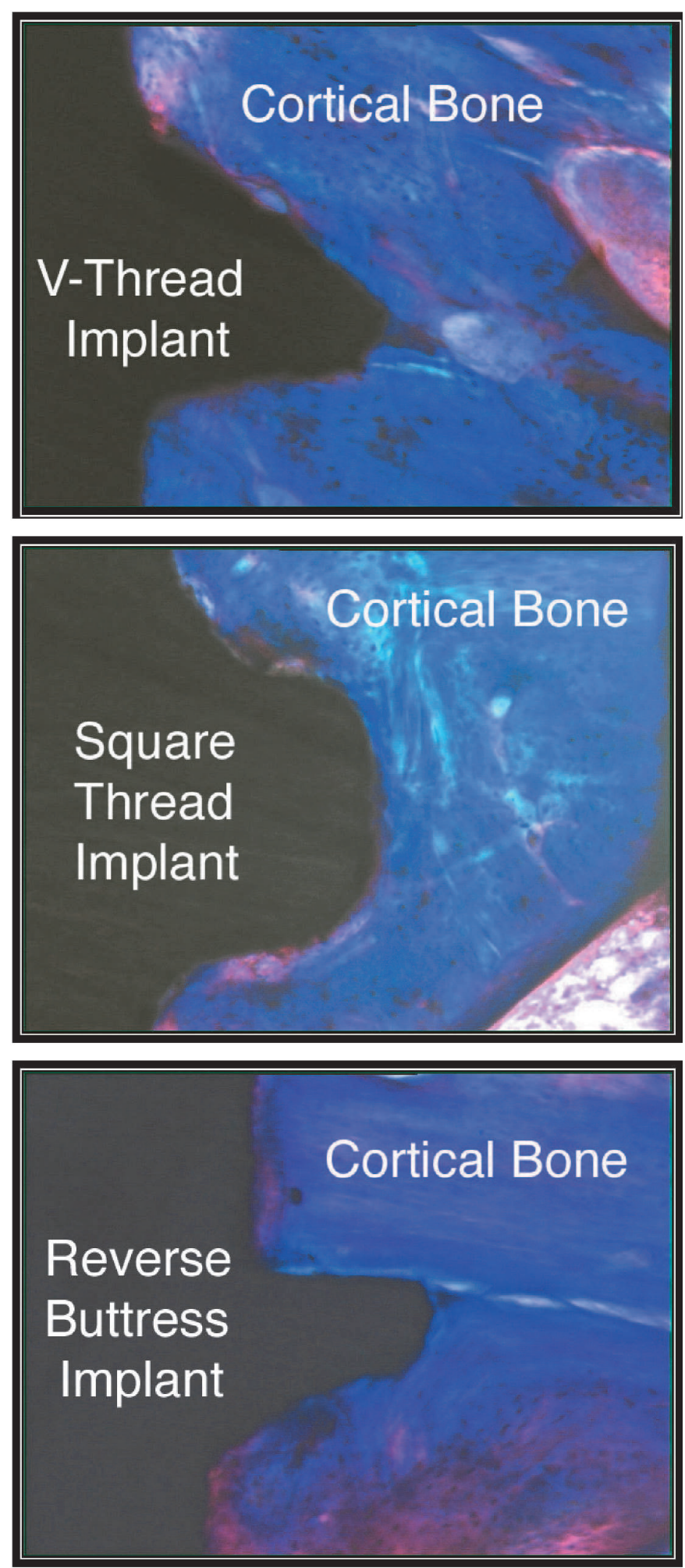

Figure 2.

Direct bone-to-implant contact of the three thread designs. absence of cover screws, multiple implants had visible bone in-growth (Fig. 3). Qualitative histologic differences among the various thread designs were not seen.

\section{Histomorphometric Analysis}

The histomorphometric findings paralleled the removal torque data. Using the one-way analysis of variance, a mean percentage of bone-to-implant contact of $65.46 \% \pm$ $9.64 \%$ was found for the $V$-thread, $63.05 \% \pm 12.45 \%$ for the reverse buttress thread, and $74.37 \% \pm 8.63 \%$ for the square thread design (Table 1). The square thread demonstrated statistically significant higher bone-toimplant contact in comparison to the $\mathrm{V}$-thread and the reverse buttress thread group $(P<0.05)$ (Table 1$)$. Comparisons were also made using repeated measures analysis of variance, which also showed statistical significance; however, the pairing was not effective due to the absence of one $\mathrm{V}$-thread section in rabbit 5 due to histological processing. As with the removal torque data, no significant differences in bone-toimplant contact were found between the V-thread and the reverse buttress thread implants (Table 1).

Radiographic bone density was analyzed on a gray scale for each of the 36 implants. The image analysis software analyzed three areas of control bone not in proximity to the implant and three areas adjacent to the thread at the internal angle between the two slopes on each side of the implant, yielding nine values for each of the 36 implants (Fig. 4). The results of the repeated measures analysis of variance with Tukey-Kramer multiple comparison test for the radiographic bone den-

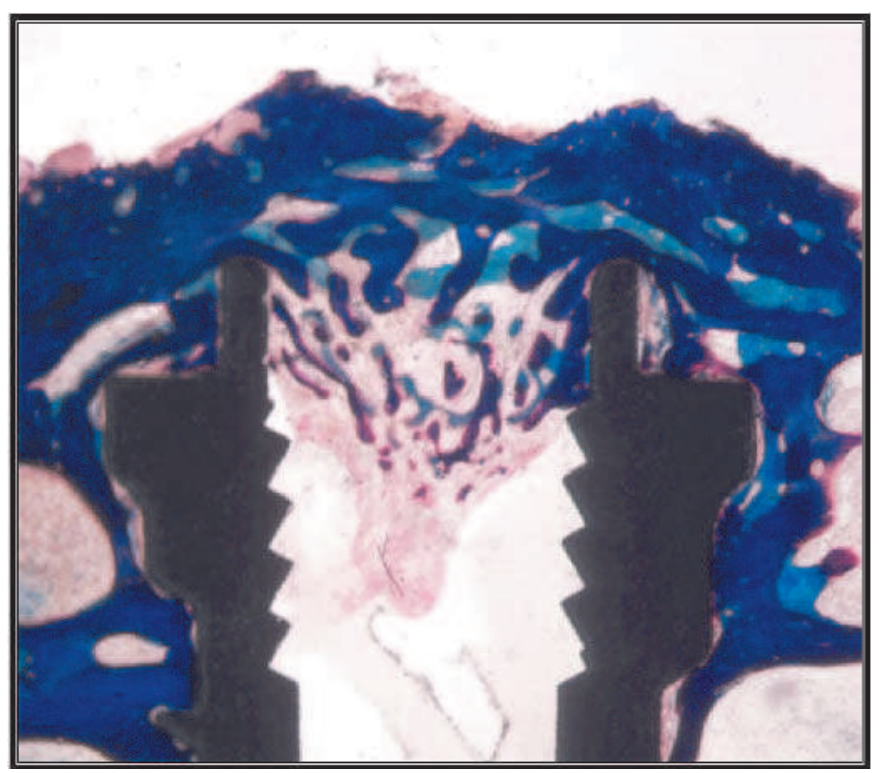

Figure 3.

Due to the absence of cover screws, multiple implants had bone growth visible into the internal component of the implant. 


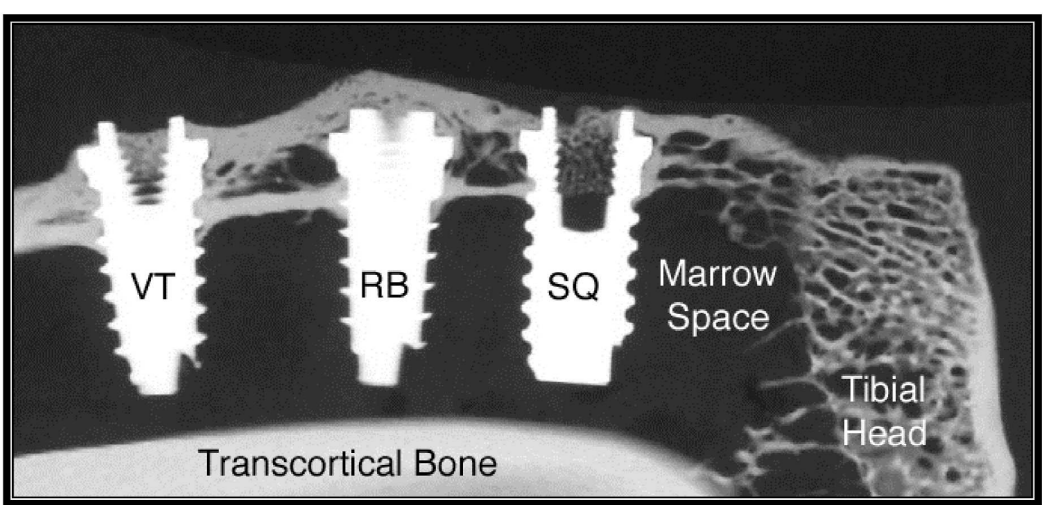

Figure 4.

Radiographic bone density. VT:V-thread; RB: reverse buttress thread; and SQ: square thread. No significant differences were found in the radiographic density results.

sity are summarized in Table 2 . The only difference found was between the control for the reverse buttress thread design, which had an average value of $122.6 \pm 35.6$, in comparison to the test for the square thread design, which had an average value of 147.6 $\pm 40.8(P<0.05)$. Since implants were not loaded, this finding is incidental as other values were not statistically different from one another $(P>0.05)$ (Table 2).

Linear regression with Pearson correlation analysis was done to compare the reverse torque removal values and percentage of BIC among the three threaded implant designs. The results of this analysis are summarized in Table 3. It was found that the square thread design had the highest correlation value of $r=0.42$, followed by the V-shaped thread at 0.33 and the reverse buttress thread at 0.31 .

Table 2.

\section{Radiographic Density Comparison of Bone Surrounding V-Shaped, Reverse Buttress, and Square Threaded Implant Designs ( $N=12$ rabbits; 36 implants)}

\begin{tabular}{lcc}
\hline & \multicolumn{2}{c}{ Radiographic Bone Density (average value) } \\
\cline { 2 - 3 } & Test & Control \\
\hline V-thread & $139.8 \pm 35.2$ & $133.2 \pm 34.4$ \\
$\begin{array}{l}\text { Reverse buttress } \\
\text { thread }\end{array}$ & $133.2 \pm 33.3$ & $122.6 \pm 35.6^{*}$ \\
Square thread & $147.6 \pm 40.8^{*}$ & $133.4 \pm 39.3$ \\
\hline
\end{tabular}

* Statistical significance $(P<0.01)$ when comparing square thread to reverse buttress control.

\section{Table 3.}

\section{Comparison of Reverse Torque Removal} Values and Percentage of Bone-to-Implant Contact Between Implant Designs ( $N=12$ rabbits; 69 implants)

\begin{tabular}{|c|c|c|c|c|c|}
\hline & & \multicolumn{3}{|c|}{ Reverse Torque } & \multirow[b]{2}{*}{ Significance } \\
\hline & & V-Thread & $\begin{array}{l}\text { Reverse } \\
\text { Buttress }\end{array}$ & $\begin{array}{l}\text { Square } \\
\text { Thread }\end{array}$ & \\
\hline \multirow{3}{*}{$\begin{array}{l}\frac{u}{n} \\
\text { do }\end{array}$} & V-thread & $r=0.33$ & 0.38 & 0.20 & \multirow{3}{*}{$P<0.000$} \\
\hline & $\begin{array}{l}\text { Reverse } \\
\text { buttress }\end{array}$ & 0.19 & 0.31 & 0.31 & \\
\hline & $\begin{array}{l}\text { Square } \\
\text { thread }\end{array}$ & 0.11 & 0.29 & 0.42 & \\
\hline
\end{tabular}

The greater BIC values were more highly correlated with the greater reverse torque removal values.

\section{DISCUSSION}

The transcortical implant model is effective in demonstrating differences in reverse torque value measurements as well as bone-to-implant contact. The data generated in this study are consistent with previous studies using a similar model, supporting evidence that commercially pure titanium is biocompatible, eliciting no acute inflammatory response.

Implant surface texture has been shown to affect the BIC. A 1995 study by Wennerberg et al. compared removal torque values on screw-shaped titanium implants with three different surface topographies..$^{21}$ In the tibia, screws blasted with $25 \mu \mathrm{m}$ particles of $\mathrm{TiO}_{2}$ needed higher reverse torque forces for removal compared to machined screws. Screws blasted with $25 \mu \mathrm{m}$ particles of titanium and $75 \mu \mathrm{m}$ particles of aluminum oxide demonstrated a higher removal torque and interfacial bone contact than did machined titanium implants with a smoother surface topography (35.4 N$\mathrm{cm}$ versus $29.2 \mathrm{~N}-\mathrm{cm}$, respectively). The use of an RBM surface in this study to rule out variation from lack of surface texture may contribute to our slightly lower reverse torque measurements, although the time frame of 3 months post-implantation was the same.

The torque values necessary for removal of implants in animals vary following specific post-insertion time intervals. Johansson and Albrektsson ${ }^{35}$ placed titanium implants into a rabbit tibia model similar to our study; however, they evaluated the removal torque values at up to 1 -year postinsertion. The various healing time intervals of 3 weeks and $1,3,6$, and 12 months correlated both to the average removal torque values and the $\mathrm{BIC}$ ratio. The average 3 -month removal torque was highly variable, peaking at $68 \mathrm{~N}-\mathrm{cm}$, which may reflect differing bone forming capac- 

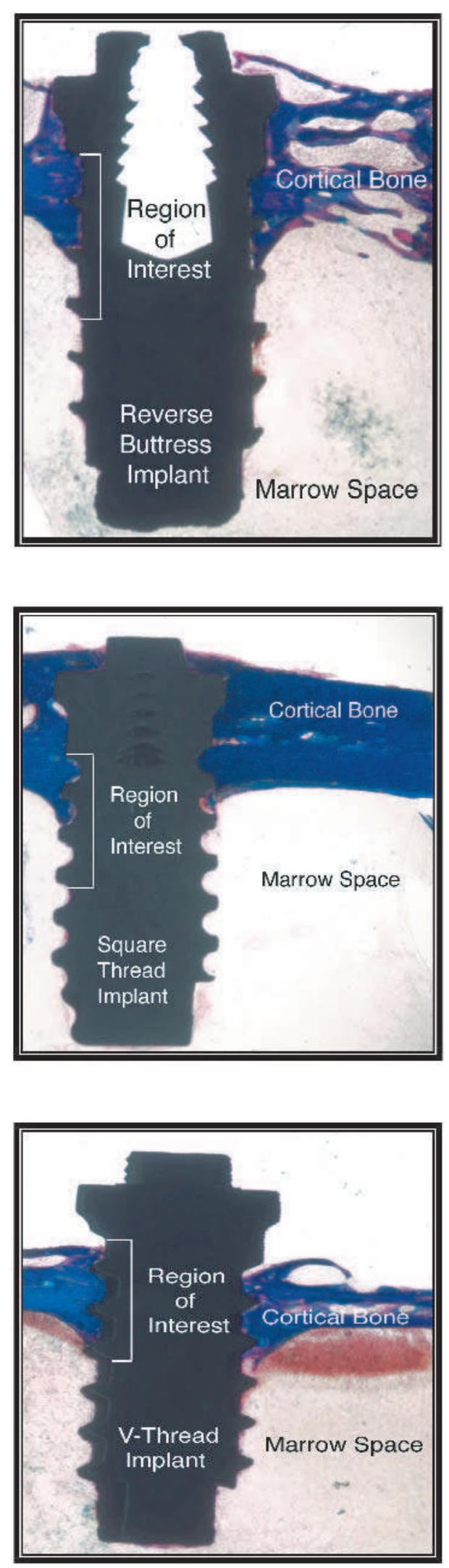

Figure 5.

Compact bone was primarily in contact with the first cortical implant threads and failed in most instances to reach the lower marrow region threads. ity between individual animals. Therefore, those animals with rapid bone formation would have completed their cellular cycle in 3 months, whereas those with less rapid bone formation would require more time. Longer followup times, therefore, would theoretically lead to less variable data. The physiologic differences between individual rabbits may explain the correlations between greater removal torque forces in one extremity and a higher percentage of BIC in the contralateral tibia.

To our knowledge, this is the first animal study to compare bone formation and reverse torque measurements of three different implant thread designs with the same surface topography in the same model. Lucchini et al. ${ }^{36}$ compared surface treatment and bone formation adjacent to two screw shaped implants of similar gross design, but with microscopically different thread designs (SEM). Test implant threads were flat at the edge, resembling a square thread design, ${ }^{\dagger \dagger}$ while controls had rounded thread edges,

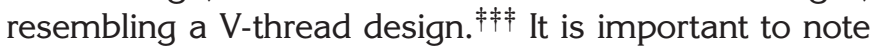
that the reverse torque test is often used as a research tool and the numbers obtained from this test may not be clinically significant or relevant. Histomorphometric analysis after 12 weeks indicated an average BIC of $68 \%$ for the test implants and $61 \%$ for the controls, which did not reach statistical significance. Despite this, the study did show a trend for greater BIC in the square thread design. Comparing this to our results, we demonstrated a significantly higher BIC in the square thread design compared to V-thread design. Differences between our findings and those of Lucchini et al. may be due, in part, to the animal models and measurement methods.

The BIC length fraction in this study was measured using the internal and external angles of the first three threads of the implant length for the various groups, which correlated to the coronal one half of the implant. It was found that compact bone was primarily in contact with the first cortical implant threads and failed in most instances to reach the lower marrow region threads, which agrees with the findings of others $21,32,37,38$ (Fig. 5). These studies all use implants with similar diameters; however, they vary in regard to the implant length and the method used to evaluate BIC. Our study used $7 \mathrm{~mm}$ implants compared to 4,5 , or $10 \mathrm{~mm}$ implants used by others. ${ }^{37,39,40}$ Other studies have calculated the BIC according to three or four consecutive best filled threads, ${ }^{21,35,38}$ whereas we utilized the first three threads of each implant regardless of bone fill.

While the implants did not carry physiologic loads, they represented models for the healing sequelae associated with two-stage dental implants where endosseous implant bodies are placed and remain unloaded during the variable healing period of several months. The findings of this animal model study may apply to clinical

\footnotetext{
$\dagger \dagger \dagger$ SERF, Decines Cedex, France.

㧊 Brånemark implants, Nobel Biocare, Yorba Linda, CA.
} 
situations in the human maxilla with regard to the soft bone quality. We found no differences in the radiographic bone density surrounding the three thread types evaluated, suggesting that thread design has no influence on initial healing of the peri-implant hard tissues.

One of the limitations associated with this study is using the rabbit tibia as our model. The tibia of a rabbit is basically hollow except the top 3 or $4 \mathrm{~mm}$; this may explain why we measured only the top three threads for the percent osseointegration and the reason for the low reverse torque scores. Because of the difference between the rabbit and human model, it does not really give us a good understanding of what would happen in humans. Nonetheless, it does provide some basic information to guide us for future studies and understanding. Other limitations include the use of a shorter implant $(<7 \mathrm{~mm})$ and no cover screw is placed for the study. Future studies with other models and longer implants with cover screws are certainly needed.

Pearson correlation analysis was done to compare the reverse torque removal values and percentage of $\mathrm{BIC}$. The greater BIC values were more highly correlated with the greater reverse torque removal values. In addition, square shaped implant threads were superior to both V-shaped and buttress thread designs, both in the percent of BIC and the torque force required for removal after initial healing. These findings are important considerations in maintaining initial implant stability during the early post-placement phase, when a majority of implant failures occur. ${ }^{15,41,42}$ This finding was unexpected, since the implants had the same dimensions and surface conditions. The perceived primary advantage of a square thread was the loading advantage to other designs, since it transfers primarily compressive forces to the bone, which is significant during immediate to early occlusal implant loading. Under these conditions the implant interface must withstand both surgical trauma and early loading conditions at the same time. Future studies will investigate differences in radiographic bone density after active loading of the three different thread designs. This may elucidate potential differences in performance between thread designs under functional conditions and generate additional useful information as to which thread design may provide a decrease in risk conditions related to stress and strain factors at the implant interface.

\section{CONCLUSIONS}

It is imperative that a greater understanding of the parameters which govern the long-term success of implants be developed. The design of an "optimal" implant requires the integration of material, physical, chemical, mechanical, biological, and economic factors. Today there is no clearly superior dental implant design. Nonetheless, thread shape is arguably becoming more important as practitioners begin to use single-stage procedures or immedi- ate loading techniques. The results of this study indicate that the square thread design may be more attractive for use in endosseous dental implant systems. Further longitudinal investigation of chronological bone changes after loading is required to support the findings of this study.

\section{ACKNOWLEDGMENTS}

This study was partially supported by the University of Michigan Periodontal Graduate Student Research Fund, by a research grant provided by Biohorizons Implant Systems, Inc., Birmingham, Alabama, and by the 2002 student research award from the International Congress of Oral Implantologists Implant Dentistry Research and Education Foundation, Montclair, New Jersey. The authors would like to thank Drs. Stephen Meraw, David Kohn, Christopher Kazor, and Mohamed Sharawy, University of Michigan School of Dentistry, Ann Arbor, Michigan, for their assistance in this project.

\section{REFERENCES}

1. Adell R, Lekholm U, Rockler B, Bränemark PI. A 15year study of osseointegrated implants in the treatment of the edentulous jaw. Int J Oral Surg 1981;10:387-416.

2. van Steenberghe D, Lekholm U, Bolender C, et al. Applicability of osseointegrated oral implants in the rehabilitation of partial edentulism: A prospective multicenter study on 558 fixtures. Int J Oral Maxillofac Implants 1990; 5:272-281.

3. Buser D, Weber HP, Bragger U, Balsiger C. Tissue integration of one-stage ITI implants: 3-year results of a longitudinal study with Hollow-Cylinder and Hollow-Screw implants. Int J Oral Maxillofac Implants 1991;6:405-412.

4. Adell R, Eriksson B, Lekholm U, Bränemark PI, Jemt T. Long-term follow-up study of osseointegrated implants in the treatment of totally edentulous jaws. Int $J$ Oral Maxillofac Implants 1990;5:347-359.

5. Nevins M, Langer B. The successful application of osseointegrated implants to the posterior jaw: A long-term retrospective study. Int J Oral Maxillofac Implants 1993;8: 428-432.

6. Henry PJ, Laney WR, Jemt T, et al. Osseointegrated implants for single-tooth replacement: A prospective 5-year multicenter study. Int J Oral Maxillofac Implants 1996;11:450-455.

7. Jemt T, Lekholm U, Grondahl K. 3-year followup study of early single implant restorations ad modum Branemark. Int J Periodontics Restorative Dent 1990;10:340-349.

8. Schmitt A, Zarb GA. The longitudinal clinical effectiveness of osseointegrated dental implants for single-tooth replacement. Int J Prosthodont 1993;6:197-202.

9. Fugazzotto PA, Gulbransen HJ, Wheeler SL, Lindsay JA. The use of IMZ osseointegrated implants in partially and completely edentulous patients: Success and failure rates of 2,023 implant cylinders up to 60+ months in function. Int J Oral Maxillofac Implants 1993;8:617-621.

10. Saadoun AP, LeGall ML. Clinical results and guidelines on Steri-Oss endosseous implants. Int $J$ Periodontics Restorative Dent 1992;12:486-495.

11. Misch CE. Density of bone: Effect on treatment plans, surgical approach, healing, and progressive bone loading. Int J Oral Implantol 1990;6:23-31.

12. Schnitman PA, Rubenstein JE, Woehrle PS, DaSilva JD, Koch GG. Implants for partial edentulism. Int J Oral 
Implantol 1988;5:33-35.

13. Albrektsson T, Lekholm U. Osseointegration: Current state of the art. Dent Clin North Am 1989;33:537-554.

14. Lekholm U, Zarb GA. Patient selection and preparation. In: Bränemark P-I, Zarb GA, Albrektsson T, eds. Tissue Integrated Prostheses. Osseointegration in Clinical Dentistry, 3rd ed. Chicago: Quintessence Publishing Co.; 1985: 199-209.

15. Friberg B, Jemt T, Lekholm U. Early failures in 4,641 consecutively placed Branemark dental implants: A study from stage 1 surgery to the connection of completed prostheses. Int J Oral Maxillofac Implants 1991;6:142-146.

16. Jaffin RA, Berman CL. The excessive loss of Branemark fixtures in type IV bone: A 5-year analysis. J Periodontol 1991;62:2-4.

17. Engquist B, Bergendal T, Kallus T, Linden U. A retrospective multicenter evaluation of osseointegrated implants supporting overdentures. Int $J$ Oral Maxillofac Implants 1988;3:129-134.

18. Carlsson L, Rostlund T, Albrektsson B, Albrektsson T. Removal torques for polished and rough titanium implants. Int J Oral Maxillofac Implants 1988;3:21-24.

19. Thomas KA, Cook SD, Renz EA, et al. The effect of surface treatments on the interface mechanics of LTI pyrolytic carbon implants. J Biomed Mater Res 1985;19:145-159.

20. Gotfredsen K, Wennerberg A, Johansson C, Skovgaard LT, Hjorting-Hansen E. Anchorage of $\mathrm{TiO}_{2}$-blasted, HAcoated, and machined implants: An experimental study with rabbits. J Biomed Mater Res 1995;29:1223-1231.

21. Wennerberg A, Albrektsson T, Andersson B, Krol JJ. A histomorphometric and removal torque study of screwshaped titanium implants with three different surface topographies. Clin Oral Implants Res 1995;6:24-30.

22. Buser D, Schenk RK, Steinemann S, Fiorellini JP, Fox CH, Stich $\mathrm{H}$. Influence of surface characteristics on bone integration of titanium implants. A histomorphometric study in miniature pigs. J Biomed Mater Res 1991;25:889-902.

23. Rieger MR, Adams WK, Kinzel GL, Brose MO. Finite element analysis of bone-adapted and bone-bonded endosseous implants. J Prosthet Dent 1989;62:436-440.

24. Rieger MR, Mayberry M, Brose MO. Finite element analysis of six endosseous implants. J Prosthet Dent 1990;63: 671-676.

25. Reilly DT, Burstein AH. The elastic and ultimate properties of compact bone tissue. J Biomech 1975;8:393-405.

26. Ivanoff CJ, Grondahl K, Sennerby L, Bergstrom C, Lekholm U. Influence of variations in implant diameters: A 3- to 5-year retrospective clinical report. Int J Oral Maxillofac Implants 1999;14:173-180.

27. Brunski JB. Biomechanical considerations in dental implant design. Int J Oral Implantol 1988;5:31-34.

28. Misch CE. Contemporary Implant Dentistry, 2nd ed. St. Louis: Mosby; 1999:329-346.

29. Bumgardner JD, Boring JG, Cooper RC Jr, et al. Preliminary evaluation of a new dental implant design in canine models. Implant Dent 2000;9:252-260.

30. Bränemark PI, Hansson BO, Adell R, et al. Osseointegrated implants in the treatment of the edentulous jaw. Experience from a 10-year period. Scand J Plast Reconstr Surg 1977;16(Suppl.):1-132.

31. Misch CE, Bidez MW, Sharawy M. A bioengineered implant for a predetermined bone cellular response to loading forces. A literature review and case report. J Periodontol 2001;72:1276-1286.
32. Sennerby L, Thomsen P, Ericson LE. A morphometric and biomechanic comparison of titanium implants inserted in rabbit cortical and cancellous bone. Int J Oral Maxillofac Implants 1992;7:62-71.

33. Sanz A, Oyarzun A, Farias D, Diaz I. Experimental study of bone response to a new surface treatment of endosseous titanium implants. Implant Dent 2001;10:126-131.

34. Dickson GR. Methods of Calcified Tissue Preparation. St. Louis: Elsevier Science Publishers; 1984:6.

35. Johansson C, Albrektsson T. Integration of screw implants in the rabbit: A 1-year follow-up of removal torque of titanium implants. Int J Oral Maxillofac Implants 1987;2: 69-75.

36. Lucchini JP, Aurelle JL, Therin M, Donath K, Becker W. A pilot study comparing screw-shaped implants: Surface analysis and histologic evaluation of bone healing. Clin Oral Implants Res 1996;7:397-404.

37. Cordioli G, Majzoub Z, Piattelli A, Scarano A. Removal torque and histomorphometric investigation of 4 different titanium surfaces: An experimental study in the rabbit tibia. Int J Oral Maxillofac Implants 2000;15:668-674.

38. Gottlander M, Albrektsson T, Carlsson LV. A histomorphometric study of unthreaded hydroxyapatite-coated and titanium-coated implants in rabbit bone. Int $J$ Oral Maxillofac Implants 1992;7:485-490.

39. Klokkevold PR, Nishimura RD, Adachi M, Caputo A. Osseointegration enhanced by chemical etching of the titanium surface. A torque removal study in the rabbit. Clin Oral Implants Res 1997;8:442-447.

40. Wigianto $R$, Ichikawa $T$, Kanitani $H$, Kawamoto $N$, Matsumoto $\mathrm{N}$, Ishizuka $\mathrm{H}$. Three-dimensional bone structure around hydroxyapatite and titanium implants in rabbits. Clin Oral Implants Res 1999;10:219-225.

41. Esposito M, Hirsch JM, Lekholm U, Thomsen P. Biological factors contributing to failures of osseointegrated oral implants. (II). Etiopathogenesis. Eur J Oral Sci 1998; 106:721-764.

42. Esposito M, Hirsch JM, Lekholm U, Thomsen P. Biological factors contributing to failures of osseointegrated oral implants. (I). Success criteria and epidemiology. Eur J Oral Sci 1998;106:527-551.

Correspondence: Dr. Hom-Lay Wang, University of Michigan School of Dentistry, 1011 N. University Ave., Ann Arbor, MI 48109-1078. Fax: 734/936-0374; e-mail: homlay@umich.edu.

Accepted for publication January 9, 2004. 